\title{
Investigating the $\mathrm{Au}-\mathrm{Cu}$ thick layers Electrodeposition Rate with Pulsed Current by Optimization of the Operation Condition
}

\author{
Hamid Babaei ${ }^{1}$, Morteza Khosravi ${ }^{2 *}$, Mohamad Reza Sovizi ${ }^{3}$, and Saeid Abedini Khorramie ${ }^{4}$ \\ ${ }^{1}$ Faculty of Chemistry, Islamic Azad University, Tehran-North Branch, Tehran, I.R. of Iran, Tehran, Iran \\ ${ }^{2}$ Faculty of Chemistry, Islamic Azad University, Tehran-North Branch, Tehran, I.R. of Iran, Tehran, Iran \\ ${ }^{3}$ Department of Chemistry, Malek Ashtar Industrial University, Tehran, I.R. of Iran, Tehran, Iran \\ ${ }^{4}$ Faculty of Chemistry, Islamic Azad University, Tehran-North Branch, Tehran, I.R. of Iran, Tehran, Iran
}

\begin{abstract}
The impact of effective parameters on the electrodeposition rate optimization of $\mathrm{Au}-\mathrm{Cu}$ alloy at high thicknesses on the silver substrate was investigated in the present study. After ensuring the formation of gold alloy deposits with the desired and standard percentage of gold with the cartage of $18 \mathrm{~K}$ and other standard karats that should be observed in the manufacturing of the gold and jewelry artifacts, comparing the rate of gold-copper deposition by direct and pulsed current was done. The rate of deposition with pulse current was significantly higher than direct current. In this process, the duty cycle parameter was effectively optimized by the"one factor at a time" method to achieve maximum deposition rate. Particular parameters in this work were direct and pulse current densities, bath temperature, concentration of gold and cyanide ions in electrolyte, $\mathrm{pH}$, agitation and wetting agent additive. Scanning electron microscopy (SEM) and surface chemical analysis system (EDS) were used to study the effect of deposition on the cross-sections of the formed layers. The results revealed that the Au$\mathrm{Cu}$ alloy layer formed with concentrations of $6 \mathrm{gr} \cdot \mathrm{L}^{-1} \mathrm{Au}, 55 \mathrm{gr} \cdot \mathrm{L}^{-1} \mathrm{Cu}, 24 \mathrm{gr} \cdot \mathrm{L}^{-1} \mathrm{KCN}$ and $1 \mathrm{ml} \cdot \mathrm{L}^{-1}$ Lauryl dimethyl amine oxide (LDAO) in the $0.6 \mathrm{~mA} \cdot \mathrm{cm}^{-2}$ average current density and $30 \%$ duty cycle, had $0.841 \mu \mathrm{m} \cdot \mathrm{min}^{-1}$ Which was the highest deposition rate. The use of electrodeposition of pure and alloy gold thick layers as a production method can reduce the use of gold metal in the production of hallow gold artifacts, create sophisticated and unique models, and diversify production by maintaining standard karats, hardness, thickness and mechanical strength. This will not only make the process economical, it will also provide significant added value to the gold artifacts. By pulsating of currents and increasing the duty cycle means reducing the pulse off-time, and if the pulse off-time becomes too short, the electric double layer would not have sufficient growth time, and its thickness decreases. These results show the effect of pulsed current on increasing the electrodeposition rate of $\mathrm{Au}-\mathrm{Cu}$ alloy confirming the previous studies on the effect of pulsed current on increasing the deposition rate of $\mathrm{Au}-\mathrm{Cu}$ alloy.
\end{abstract}

Keywords : Alloy Electrode position, Au-Cu Bath Composition, Average Current Density, Optimization of Deposition Rate, Duty Cycle, Formation of Layers and Gold Percentage

Received : 8 April 2019, Accepted : 26 December 2019

\section{Introduction}

The modern electroplating was first introduced in 18 th century [1]. Until the present, many studies have been done of electrodeposition. Giurlani et al. [2] have provided a brief history of the use of this method. In electrodeposition different parameters

*E-mail address: m_khosravi@iau-tnb.ac.ir

DOI: https://doi.org/10.33961/jecst.2019.00087

This is an open-access article distributed under the terms of the Creative Commons Attribution Non-Commercial License (http://creativecommons.org/licenses/by-nc/4.0) which permits unrestricted non-commercial use, distribution, and reproduction in any
medium, provided the original work is properly cited. such as the electrolytic composition, deposition temperature, applied current density, and $\mathrm{pH}$ of the solution can be regulated [3]. Electrodeposition of gold and its alloys in high thicknesses, which can be used in the manufacturing of hallow gold-jewelry artifacts, dentistry and watch cases, is a process that produces pure gold or layer by layer alloys with a thickness of at least 0.005 inches [4]. Alloy gold layers, which are formed by the electrochemical deposition method, are characterized by a certain gold percentage, mechanical properties, hardness and ductility for making gold artifacts. Gold electrolytes are widely 
utilized in the production of hollow artifacts of goldjewelry and watch cases, which have standard gold values, by using an electrochemical deposition method with various combinations of alloy baths. These layers are very shiny, uniform, ductile and yet capable of creating more thicknesses [5].

Such layers are usually formed with cyanide based gold solutions with a concentration of gold up to $10 \mathrm{gr} \cdot \mathrm{L}^{-1}$, and thicknesses of about 150 to $200 \mu \mathrm{m}$ are obtained at a maximum current density of $8 \mathrm{~mA} \cdot \mathrm{cm}^{-2}$ [6]. Formation thick layers by these solutions requires a relatively large amount of time. The two main types of alloyed baths used to produce thick electrodeposits include: (1) alkaline-cyanide baths, mostly of gold-copper-cadmium and gold-copper baths, and (2) acidic baths containing citrate and EDTA compounds [6].

In recent years, novel electrochemical processes have developed $[7,8]$. The features of products in electrodeposited metals is influenced by various deposition parameters [9]. There are many recorded reports about the use of pulsed current in the thick deposition of gold and its alloys. Some of the electrolytes have used high concentrations of gold and even gold anodes are suggested for these baths. Reaching proper deposition rate is one of the basic issues in creating thick gold and its alloys in the production of gold artifacts by electroforming [10-11]. The rate of gold electrodeposition with these solutions to produce high thickness layers in alkaline solutions and especially cyanide is at about 0.5 micron per minute, but it is still low for the formation of thick, pure and alloyed gold alloys. Increasing the current density may play a very important role in the deposition rate [12-13], as well as the surface roughness [14-15]. However, increasing the direct current density reduces the quality of the deposited layers. One of the goals of using pulse current is to achieve the accepted thickness at a shorter time, having the desired alloying properties, as well as its mechanical properties. In order to compare the structure of deposits and the rate of deposition with direct current and pulse current, the average current rate of the pulsed current is used [12-13].

Some of the most important advantages of deposition with pulsed current, especially in the formation of thick layers, include increased deposition rate and efficiency, the formation of higher density and finegrained layers, much less variation in the thickness of the layers in different points of the surface and less need for organic additives than direct current [16].

The use of pulsed current provides the basis for formation a denser layer than direct current, which results in an increase in the nucleation rate and the deposition of fine-grained layers [17-18]. In direct current deposition, the only variable is the current density, but in pulsed electrodeposition, at least three parameters including the pulse height $\left(\mathrm{I}_{\mathrm{p}}\right)$, on-time and off-time of pulses, which are different in deposition processes, can be optimized. Typically, the pulse on-time can vary from 1.0 to 9.9 milliseconds and the pulse off-time varies from 1 to 99 milliseconds. Using an ampere meter will show the average current density. In order to have the same deposition rate using pulse current instead of direct current, the average current density should be equal to direct current [19]. By using the pulse current at each instant, the current density can be adjusted by the time the pulse is switched on and off. By carefully selecting the optimal electrochemical parameters of metals and alloys deposition, the properties of the deposited layers can be very carefully controlled. By adjusting the pulse current parameters, in comparison with the direct current and passing the same values of electricity from the electrolyte, there will be a significant increase in the deposition rate of the layers [11].

The aim of this investigation according to the low electroforming rate of alloyed gold, was the deposition of $\mathrm{Au}-\mathrm{Cu}$ layers by direct and pulsed current and optimization of working conditions by pulse current to the achieve maximum deposition rate which can be higher than some commercial processes.

\section{Experimental}

\subsection{Materials}

Potassium cyanide, Copper (I) Cyanide, Lauryl Dimethyl Amine Oxide (LDAO), Sodium hydroxide and Sulfuric acid were purchased from Merck and potassium gold cyanide was purchased from Umicore $\mathrm{GmbH}$.

\subsection{Research Instruments}

Electrodeposition bath was a Pyrex glass with a diameter of $110 \mathrm{~mm}$ and a height of $140 \mathrm{~mm}$ in the volume of one liter. The temperature control in the bath was performed with an IKA C-MAG HS7 heater with accuracy of $\pm 0.1{ }^{\circ} \mathrm{C}$. The anodes are platinized- 
titanium mesh beads with dimensions of $80 \times 100 \mathrm{~mm}$, which were fixed in the wall of a beaker. Pure silver was prepared as cathode in the dimensions of $1 \mathrm{~cm}^{2}$ and $1 \mathrm{~mm}$ thick by casting, and then by finishing and polishing operations [5]. The agitation of the solution was carried out by a magnetic stirrer. The $\mathrm{pH}$ of the bath was also adjusted by the HANNA HI 98107 pH meter. All experiments were performed by the pulsed power supply of the SL20 PRC switch mode, made in Iran. The current density (pulse and direct) in the range of (2$12 \mathrm{~mA} \cdot \mathrm{cm}^{-2}$ ) was used to study the thickness and deposition rate of the layers. Before and after deposition, weighing of the cathodes was carried out using the Sartorius GK1203 analytical balance with a precision of $0.0001 \mathrm{~g}$. EDX Bruker XFlash6110 to determine the percentage of gold and copper elements in the alloy were carried out. The thickness evaluation of the formed layers under optimum conditions of pulsed current was done by SEM CamScan MV2300 scanning electron microscopy.

\subsection{Procedure}

In this research, having the necessary conditions for the formation of gold-copper alloy layers with a specified percentage (standard karat of gold, wt.75\% $\mathrm{Au}$ ), and comparison of the deposited alloy layers with direct and pulsed current at $10 \%$ duty cycle, resulted in an approximate accepted gold percentage in the deposited alloys. In order to achieve the maximum rate of gold-copper alloy deposition, by using pulse current, the optimization of deposition rate was done by changing the duty cycles from 20 to $90 \%$. Duty cycle values changed with other factors remaining constant, this method is called "one factor at a time" [20].

During the pulse electrodeposition, the percentage of duty cycle $(\% \theta)$ represents the percentage of total pulse cycle time [11] and is calculated from the following equation:

$$
\% \text { Duty Cycle }=\frac{t_{\text {on }}}{t_{\text {on }}+t_{\text {off }}} \times 100
$$

In this process, the average flow density $\left(I_{\text {avg }}\right)$ is:

$$
\text { Pulse height or Iavg }=I_{p_{\text {on }}} \frac{t_{\text {on }}}{t_{\text {off }}}
$$

Where $I_{\text {avg }}$ and $I_{p}$ are the mean values of the average current density and pulse current density [11].
The theory thickness $\left(\mathrm{T}_{\text {theory }}\right)$ in micrometers, also follows the relation

$$
T_{\text {th }}=\frac{m_{a} \times 10^{4}}{A \times \rho_{\text {alloy }}}
$$

It is calculated that $\mathrm{m}_{\mathrm{a}}$ is the mass of the deposited layer in grams, $\mathrm{A}$ is the cathode surface area in $\mathrm{cm}^{2}$ and $\rho_{\text {alloy, }}$ and the density of the deposited layer is in grams per cubic centimeter [21].

In this study, the pure silver cathodes were used as substrate with dimension of $1 \mathrm{~cm} \times 1 \mathrm{~cm}$. Prior to the electrodeposition, the samples were catholically degreased with a $10 \%$ sodium hydroxide solution, and washed with ion-free water and neutralized with $5 \%$ sulfuric acid solution and finally washed with D.I water [5]. The electrodeposition bath was a $1000 \mathrm{~mL}$ cylindrical beaker and platinized titanium anodes were used. The laboratory heater/stirrer was used for heating and agitation. A gold-copper alloy can generally be deposited from a cyanide bath containing $\mathrm{KCN}, \mathrm{K}_{2} \mathrm{Cu}(\mathrm{CN})_{3}, \mathrm{KAu}(\mathrm{CN})_{2}$ and a small amount of $\mathrm{C}_{14} \mathrm{H}_{31} \mathrm{NO}$ as the wetting agent [22-23]. The deposition process was carried out by the pulsed power supply (SL20 PRC) switch mode and the deposition time in all of samples was $240 \mathrm{~min}$. The current density (pulse height) values were $I_{p}=2-12 \mathrm{~mA} \cdot \mathrm{cm}^{-2}$, the on time $\left(\mathrm{T}_{\mathrm{on}}\right)$ pulsed was $0.01 \mathrm{~s}-0.09 \mathrm{~s}$ and the off time $\left(\mathrm{T}_{\text {off }}\right)$ pulsed were varied as invert on time values. After electrodeposition, the samples were removed from the electrolyte solution, washed with distilled water and dried at $70^{\circ} \mathrm{C}$ hot air and annealed at $450^{\circ} \mathrm{C}$ for $20 \mathrm{~min}$. The layers of the gold-copper alloy was the formation on the silver substrate from $18-35 \mathrm{gr} \cdot \mathrm{L}^{-1}$ Potassium cyanide, $55 \mathrm{gr} \cdot \mathrm{L}^{-1}$ Copper as Potassium copper (I) cyanide, 5-10 $\mathrm{gr} \cdot \mathrm{L}^{-1}$ Gold as Potassium gold cyanide and $0.5-1.75 \mathrm{~mL} \cdot \mathrm{L}^{-1}$ LDAO [24]. The $\mathrm{pH}$ of the solution was adjusted to 11.5-12.5 [23] by adding $\mathrm{NaOH}$ and/or $\mathrm{H}_{3} \mathrm{PO}_{4} 10 \%$, at $60-70\left({ }^{\circ} \mathrm{C}\right)$ temperature. In this work, first, the current density was in the range of 2-12 $\left(\mathrm{mA} \cdot \mathrm{cm}^{-2}\right)$, the gold and potassium cyanide concentration, the bath temperature, $\mathrm{pH}$, agitation at 50-175 rpm and the amount of additive were carried out by one factor at a time method, in order to check the rate of deposition of the $\mathrm{Au}-\mathrm{Cu}$ deposited, alloys (containing approximate wt.\% $75 \mathrm{Au}$ ) were optimized [25]. Due to the possibility of changes in the deposited alloy karats, changing in the concentration of copper in the solution were not done, and in all experiments, the concentration of copper was con- 
stant and $55 \mathrm{gr} \cdot \mathrm{L}^{-1}[26]$. Then, the deposition rate and the efficiency of the layers were investigated by pulsating with the help of changing the parameters of various duty cycles. Pulse on and off time parameters were set at 0.01 seconds [19]. Formation of layers with the same values of electricity, will be thicker than the direct current if the pulse current is applied. By applying a certain amount of potential during a pulse cycle, the potential decreases with a pulse offtime, and because of this, the electrochemical reduction is also observed during the off-time period [13].

Thickness measurement of the formed layers was performed using the SEM CamScan MV2300 scanning electron microscope and the alloy composition determination were done with EDXBruker XFlash6110.

\section{Results and Discussion}

In this investigation, a thick gold-copper layer was deposited by the direct and pulsed current on pure silver substrate by a cyanide base solution. The optimized working conditions were selected for the formation of a gold-copper alloy layer from a range of parameters including current density, gold and potassium cyanide concentration, temperature, $\mathrm{pH}$, agitation, wetting agent and duty cycle at 2-12 $\left(\mathrm{mA} \cdot \mathrm{cm}^{-2}, 5-10\left(\mathrm{gr} \cdot \mathrm{L}^{-1}\right), 18-35\left(\mathrm{gr} \cdot \mathrm{L}^{-1}\right), 60-70^{\circ} \mathrm{C}\right.$, 11.5-12.5, 50-175 rpm, $0.5-1.75 \mathrm{ml} \cdot \mathrm{L}^{-1}$ [23-27]. The details of the optimization process are discussed in the following sections.

\subsection{Determination of the Au-Cu electrodeposition condition}

The deposition of gold-copper with the $6 \mathrm{~mA} \cdot \mathrm{cm}^{-2}$, direct current density was done according to previous works where the bath composition $\left(\right.$ at $\left.65^{\circ} \mathrm{C}\right)$ was $7.5\left(\mathrm{gr} \cdot \mathrm{L}^{-1} \mathrm{Au}\right.$ asKAu$(\mathrm{CN})_{2}, 55\left(\mathrm{gr} \cdot \mathrm{L}^{-1} \mathrm{Cu}\right.$ as $\mathrm{K}_{2} \mathrm{Cu}(\mathrm{CN})_{3}$ and $24\left(\mathrm{gr} \cdot \mathrm{L}^{-1}\right) \mathrm{KCN}$ [23-27]. This bath composition is used to produce standard $18 \mathrm{k}$ gold alloy layers for gold-jewelry artifacts and watch cases [24-27]. The thickness of the deposited layer by the above gold-copper solution was investigated by SEM (Fig. 1).

The mentioned bath composition produced repeatable gold-copper electrodeposited layers with standard and well-considered gold content in deposited alloy [28]. Table 1 shows the results of gold-copper deposition by direct current and the deposited mass, gold percent and thickness of layer in $240 \mathrm{~min}$.

\subsection{Effect of pulsed current on electrodeposition rate}

By applying the same amount of current density values, the pulse current will be significantly increased in comparison with direct current [11]. The deposition of metallic nano films by uniform and defect-free structures is of significant value [29]. For optimization of the deposition rates for the formation of deposits with the thicker layers, under the following conditions (Table 2), gold-copper deposition was done.

$\mathrm{Au}-\mathrm{Cu}$ deposited layer was achieved with pulsed currents at $10 \%$ duty cycle $(0.01 \mathrm{~s}$ On-time and $0.09 \mathrm{~s}$

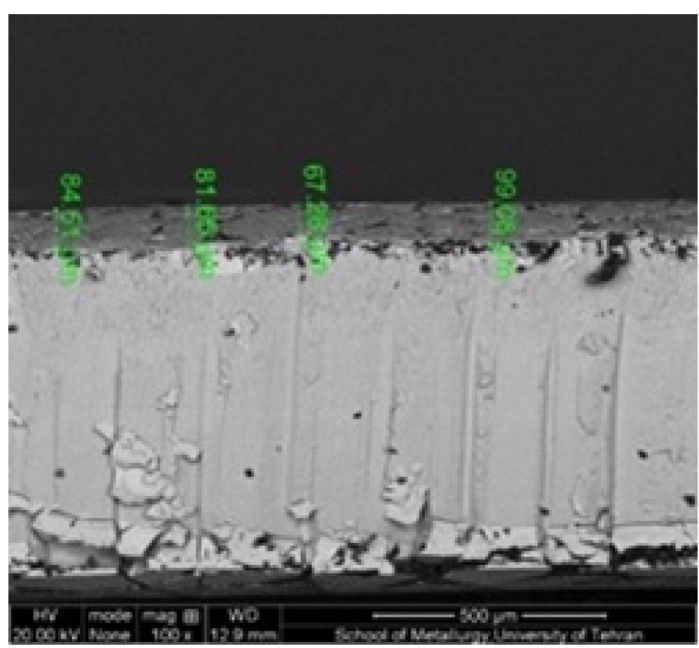

Fig. 1. The SEM image of average thickness of the deposited layer cross-section, $82 \mu \mathrm{m}$ with $6 \mathrm{~mA} \cdot \mathrm{cm}^{-2}$ direct current within $240 \mathrm{~min}$

Table 1. Specifications of the gold-copper deposition by direct current (deposited mass, gold content and thickness of layer) in $240 \mathrm{~min}$.

\begin{tabular}{cccccccccc}
\hline \hline \multirow{2}{*}{$\begin{array}{c}\text { Direct current Density } \\
\left(\mathrm{mA} \cdot \mathrm{cm}^{-2}\right)\end{array}$} & $\begin{array}{c}\mathrm{m}_{\text {alloy }} \\
(\mathrm{mgr})\end{array}$ & \multicolumn{2}{c}{ Alloy Composition $(\mathrm{ppt})$} & $\begin{array}{c}\mathrm{A} \\
\left(\mathrm{cm}^{2}\right)\end{array}$ & $\begin{array}{c}\rho_{\text {alloy }} \\
\left(\mathrm{gr}^{2} \cdot \mathrm{cm}^{-3}\right)\end{array}$ & $\begin{array}{c}\mathrm{T}_{\mathrm{th}} \\
(\mu \mathrm{m})\end{array}$ & $\begin{array}{c}\mathrm{T}_{\text {avg }} \\
(\mu \mathrm{m})\end{array}$ & $\begin{array}{c}\tau \\
(\mu \mathrm{m})\end{array}$ \\
\hline 6 & 82.327 & 267 & 733 & 1 & 14.49 & 88 & 82 & 240 \\
\hline
\end{tabular}


Table 2. Optimized conditions of the Au-Cu electrodeposition for stabilization of gold content in deposited alloy (Approx. wt. \% $75 \mathrm{Au})$

\begin{tabular}{cccccccc}
\hline \hline $\begin{array}{c}\text { Direct Current Density } \\
\left(\mathrm{mA} \cdot \mathrm{cm}^{-2}\right)\end{array}$ & $\begin{array}{c}C_{A U^{+}} \\
\left(\mathrm{gr} \cdot \mathrm{L}^{-1}\right)\end{array}$ & $\begin{array}{c}C_{C N^{+}} \\
\left(\mathrm{gr} \cdot \mathrm{L}^{-1}\right)\end{array}$ & $\begin{array}{c}C_{C N^{-}} \\
\left(\mathrm{gr} \cdot \mathrm{L}^{-1}\right)\end{array}$ & $\begin{array}{c}\text { Agitation } \\
(\mathrm{rpm})\end{array}$ & $\begin{array}{c}\text { Temp } \\
\left({ }^{\circ} \mathrm{C}\right)\end{array}$ & $\begin{array}{c}\text { Additive } \\
\left(\mathrm{ml} \cdot \mathrm{L}^{-1}\right)\end{array}$ \\
\hline 6 & 66 & 55 & 24 & 100 & 66 & 12 & 1 \\
\hline
\end{tabular}

Table 3. Effect of average pulse current density on deposited mass, gold content and thickness of layer in 240 min under optimum conditions

\begin{tabular}{|c|c|c|c|c|c|c|c|c|c|c|c|}
\hline \multirow{2}{*}{$\begin{array}{l}\mathrm{T}_{\text {on }} \\
(\mathrm{s})\end{array}$} & \multirow{2}{*}{$\begin{array}{l}\mathrm{T}_{\text {off }} \\
(\mathrm{s})\end{array}$} & \multirow{2}{*}{$\begin{array}{c}\theta \\
(\%)\end{array}$} & \multirow{2}{*}{$\begin{array}{c}\text { Pulse height } \\
\mathrm{I}_{\mathrm{avg}} \\
\left(\mathrm{mA} \cdot \mathrm{cm}^{-2}\right)\end{array}$} & \multirow{2}{*}{$\begin{array}{l}\mathrm{m}_{\text {alloy }} \\
\text { (gr) }\end{array}$} & \multicolumn{2}{|c|}{$\begin{array}{l}\text { Alloy Composition } \\
\text { (ppt) }\end{array}$} & \multirow{2}{*}{$\underset{\left(\mathrm{cm}^{2}\right)}{\mathrm{A}}$} & \multirow{2}{*}{$\begin{array}{c}\rho_{\text {alloy }} \\
\left(\mathrm{gr} \cdot \mathrm{cm}^{-3}\right)\end{array}$} & \multirow{2}{*}{$\begin{array}{c}\mathrm{t} \\
(\mathrm{min})\end{array}$} & \multirow{2}{*}{$\begin{array}{c}\mathrm{T}_{\text {th }} \\
(\mu \mathrm{m})\end{array}$} & \multirow{2}{*}{$\begin{array}{r}T_{\text {avg }} \\
(\mu \mathrm{m})\end{array}$} \\
\hline & & & & & $\mathrm{Cu}$ & $\mathrm{Au}$ & & & & & \\
\hline 0.01 & 0.09 & 10 & 0.6 & 153.211 & 256 & 744 & 1 & 14.92 & 240 & 160 & 151 \\
\hline
\end{tabular}

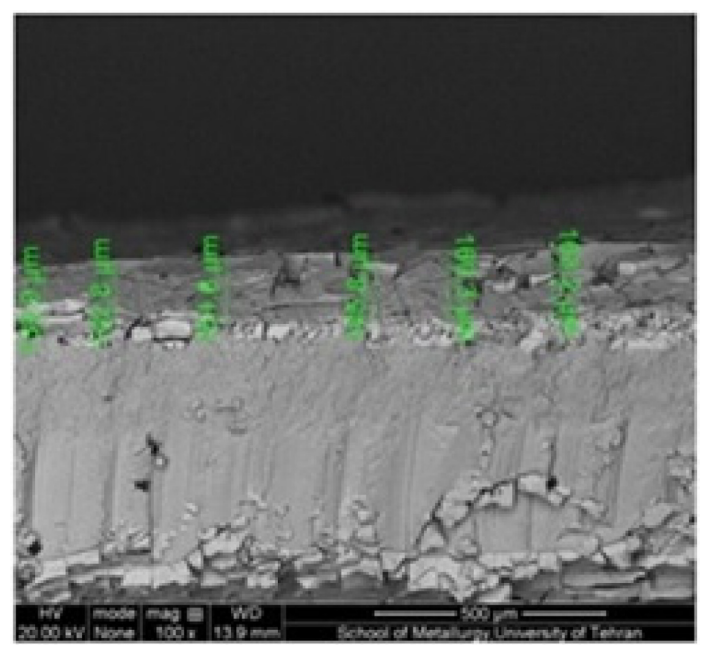

Fig. 2. The SEM image of average thickness of the deposited layer cross-section, $151 \mu \mathrm{m}$ with $0.6 \mathrm{~mA} \cdot \mathrm{cm}^{2}$ Current $(10 \%$ duty cycle, $0.01 \mathrm{~s}$ on-time and $0.09 \mathrm{~s}$ offtime), within 240 min.

Off-time), under the same conditions presented in Table. 2. Fig. 2 shows the SEM image of the cross section of $\mathrm{Au}-\mathrm{Cu}$ deposit with $10 \%$ duty cycle of pulsed current. The average layer thickness formed by the pulse current is about $151 \mu \mathrm{m}$.

\subsection{Effect of the duty cycles percentage variation on the $\mathrm{Au}-\mathrm{Cu}$ electrodeposition rate}

In the following, the effect of changes in the duty cycle percentage on the electrodeposition rate of the $\mathrm{Au}-\mathrm{Cu}$ alloy was investigated by keeping the optimized parameters constant. Fig. 3 shows the SEMEDX images of the cross-section of all formed layers with different duty cycles (20-90\%) that are deposited with the same values of other parameters.

The Au-Cu alloy which deposited layers in the $30 \%$ duty cycle ( $0.03 \mathrm{~s}$ on-time and $0.07 \mathrm{~s}$ off-time), has a deposition rate of $0.841\left(\mu \mathrm{m} \cdot \mathrm{min}^{-1}\right)$. This rate is higher than some of the commercial processes of the gold electroformed artefacts with an average of about $0.5\left(\mu \mathrm{m} \cdot \mathrm{min}^{-1}\right)[23]$. In duty cycles larger than $30 \%$, a significant decrease was observed in the deposition rate of $\mathrm{Au}-\mathrm{Cu}$ alloy, which was done in the same conditions. Increasing the duty cycle means reducing the time of the off-time [11], and so a decrease in deposition rate [30]. If the pulse time is too short, it means that the electrical double layer has not had enough growth opportunity, it is very thin and in fact, there will be no difference with the mode of direct current deposition [11]. Table 4 shows the effect of duty cycle variations with $0.6 \mathrm{~mA} \cdot \mathrm{cm}^{-2}$ on the deposited mass, thickness and deposition efficiency of the Au$\mathrm{Cu}$ alloy. Electrodeposition at $30 \%$ duty cycle was selected as optimum duty cycle to reach the highest deposition rate $\left(0.841 \mu \mathrm{m} \cdot \mathrm{min}^{-1}\right)$ and the results of this effect with the calculated values of the theory have been compared. This decrease in deposition rate is justified by increasing duty cycle at smaller offtimes and thinning of the double electric layer [20]. The formation of thick alloyed gold layers for the production of gold-jewelry hallow artifacts has been commercialized by electroforming machines and their programmable systems have been developed. One of the main problems with this equipment is the low speed of the deposition of layers, which is rarely higher than $0.5 \mu \mathrm{m} \cdot \mathrm{min}^{-1}$, and according to the need for a thickness of about $300 \mu \mathrm{m}$, it will take more 

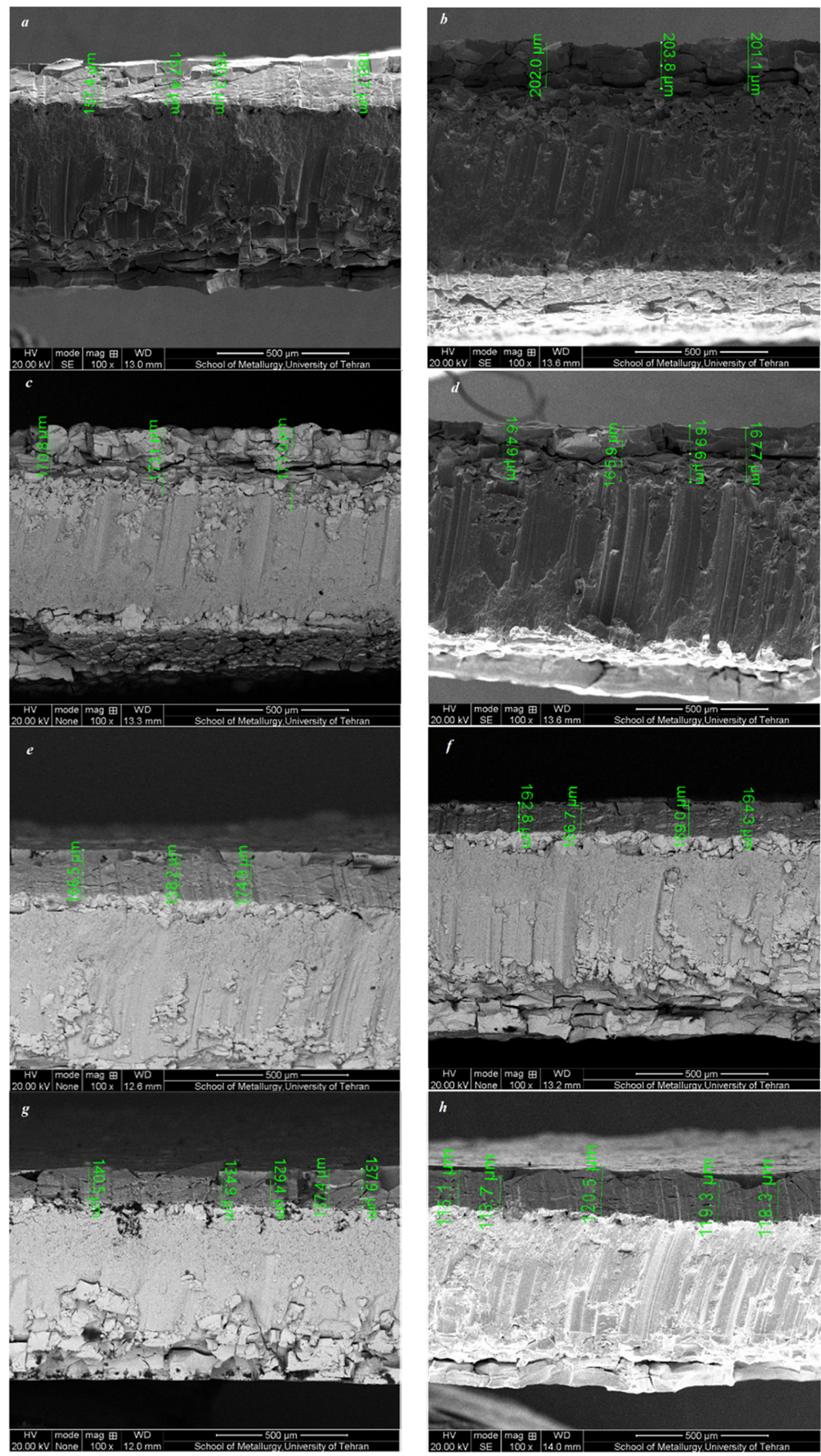

Fig. 3. SEM cross section images of Au-Cu alloy (a to $\mathrm{h}$ ) at the same operating condition, at $20 \%$ duty cycle contents $162 \mu \mathrm{m}$ (a), 30\% duty cycle contents $202 \mu \mathrm{m}$ (b), $40 \%$ duty cycle contents $174 \mu \mathrm{m}$ (c), $50 \%$ duty cycle contents $167 \mu \mathrm{m}$ (d), and $60 \%$ duty cycle contents $166 \mu \mathrm{m}$ (e), $70 \%$ duty cycle contents $165 \mu \mathrm{m}$ (f), $80 \%$ duty cycle contents $136 \mu \mathrm{m}(\mathrm{g})$, and $90 \%$ duty cycle contents $117 \mu \mathrm{m}(\mathrm{h})$. 
Table 4. Influence of duty cycle variation (20-90\%) on formed mass, deposition rate and composition of gold-copper alloy, and comparison of experimental values of the deposition thickness with calculated values.

\begin{tabular}{|c|c|c|c|c|c|c|c|c|c|c|c|c|}
\hline \multirow[t]{2}{*}{$\begin{array}{l}\mathrm{T}_{\text {on }} \\
(\mathrm{s})\end{array}$} & \multirow[t]{2}{*}{$\begin{array}{l}\mathrm{T}_{\text {off }} \\
(\mathrm{s})\end{array}$} & \multirow[t]{2}{*}{$\begin{array}{c}\theta \\
(\%)\end{array}$} & \multirow[t]{2}{*}{$\begin{array}{c}\mathrm{m}_{\text {alloy }} \\
(\mathrm{gr})\end{array}$} & \multirow{2}{*}{$\begin{array}{l}\text { Pulse height } \\
\text { Iavg } \\
\left(\mathrm{mA} \cdot \mathrm{cm}^{-2}\right)\end{array}$} & \multicolumn{2}{|c|}{$\begin{array}{c}\text { Alloy } \\
\text { composition } \\
\text { (ppt) }\end{array}$} & \multirow[t]{2}{*}{$\begin{array}{c}\mathrm{A} \\
\left(\mathrm{cm}^{2}\right)\end{array}$} & \multirow[t]{2}{*}{$\begin{array}{c}\text { ralloy } \\
\left(\text { gr.com }^{-3}\right)\end{array}$} & \multirow[t]{2}{*}{$\begin{array}{l}\text { Tth } \\
(\mu \mathrm{m})\end{array}$} & \multirow[t]{2}{*}{$\begin{array}{l}\text { Tavg } \\
(\mu \mathrm{m})\end{array}$} & \multirow[t]{2}{*}{$\begin{array}{c}\mathrm{t} \\
(\min )\end{array}$} & \multirow[t]{2}{*}{$\underset{\left(\mathrm{mm} \cdot \mathrm{min}^{-1}\right)}{\text { Ravg }}$} \\
\hline & & & & & $\mathrm{Au}$ & $\mathrm{Cu}$ & & & & & & \\
\hline 0.02 & 0.08 & 20 & 0.255 & 0.6 & 732 & 267 & 1 & 14.74 & 173 & 163 & 240 & 0.679 \\
\hline 0.03 & 0.07 & 30 & 0.313 & 0.6 & 744 & 256 & 1 & 14.90 & 210 & 202 & 240 & 0.841 \\
\hline 0.04 & 0.06 & 40 & 0.272 & 0.6 & 735 & 265 & 1 & 14.79 & 184 & 174 & 240 & 0.725 \\
\hline 0.05 & 0.05 & 50 & 0.254 & 0.6 & 727 & 273 & 1 & 14.65 & 174 & 167 & 240 & 0.695 \\
\hline 0.06 & 0.04 & 60 & 0.258 & 0.6 & 743 & 257 & 1 & 14.90 & 173 & 166 & 240 & 0.687 \\
\hline 0.07 & 0.03 & 70 & 0.254 & 0.6 & 731 & 269 & 1 & 14.74 & 172 & 165 & 240 & 0.683 \\
\hline 0.08 & 0.02 & 80 & 0.211 & 0.6 & 727 & 273 & 1 & 14.65 & 144 & 136 & 240 & 0.566 \\
\hline 0.09 & 0.01 & 90 & 0.185 & 0.6 & 740 & 260 & 1 & 14.91 & 124 & 117 & 240 & 0.487 \\
\hline
\end{tabular}

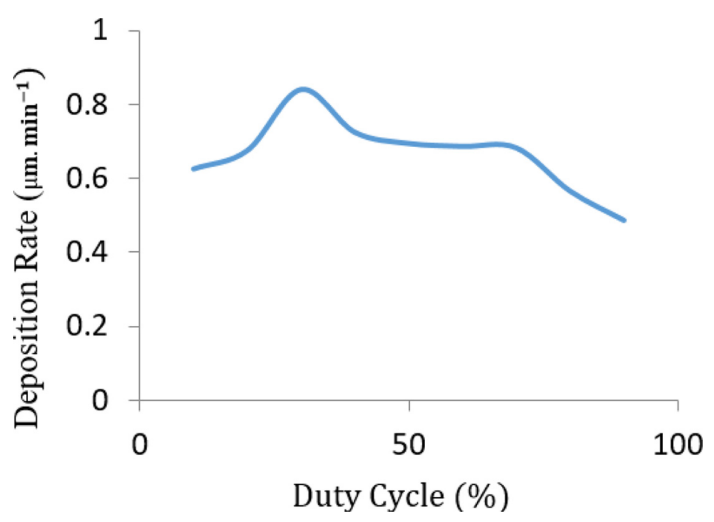

Fig. 4. Effect of different duty cycles on the average rate of Au-Cu alloy electro-deposition.

than $10 \mathrm{hr}$, the rate of production processes of hallow gold-jewelry artifacts by electrodeposition method significantly reduces. By optimizing the process in these systems, we can achieve higher deposition rates, which is the main objective of this study [27].

The curves of average deposition rate with duty cycle's percent are shown in Fig. 4.

\section{Conclusions}

According to the results of this study, electrodeposition of gold-copper alloyed layers with a cyanide base solution containing $6 \mathrm{gr} \cdot \mathrm{L}^{-1} \mathrm{Au}, 55 \mathrm{gr} \cdot \mathrm{L}^{-1} \mathrm{Cu}$, $24 \mathrm{gr} \cdot \mathrm{L}^{-1} \mathrm{KCN}$ and $1 \mathrm{gr} \cdot \mathrm{L}^{-1} \mathrm{LDAO}$ by pulsed current was faster than direct current. The deposition of the $\mathrm{Au}-\mathrm{Cu}$ alloy by pulsed current is a controllable method for the formation of layers with standard values of gold percentage in alloy gold deposited. In this method, the working conditions (current density, concentrations of gold and cyanide ions, temperature, $\mathrm{pH}$, agitation and wetting agent) and pulse electrodeposition parameters (duty cycle and current density) were effective variables in this study. In the deposition of $\mathrm{Au}-\mathrm{Cu}$, to the formation a layer with an acceptable rate of deposition, LDAO can be used as a wetting agent to create thicker layers. It has also been found that the average current density is $0.6 \mathrm{~mA} \cdot \mathrm{cm}^{-2}$ and the duty cycle is $30 \%$ with the highest percentage of gold in the layer and the rate of electrodeposition on pure silver substrates, and these are the optimal values. It was also observed that the duty cycles more than $30 \%$ lead to lower deposition rate, thickness of the layer and the cathodic efficiency of the direct current were lower than the pulsed current in gold-copper deposition.

\section{Acknowledgement}

We gratefully acknowledge the invaluable support provided by Phoenix Yassin Chemistry Co., Precious Metals Research \& Development lab.

\section{References}

[1] J.E. Greene, Appl. Phys. Rev., 2014, 1(3), 302-310.

[2] W. Giurlani, G. Zangari, F. Gambinossi, M. Passaponti, E. Salvietti, F. Di Benedetto, S. Caporali and M. Innocenti, Coatings, 2018, 8(3), 136-143.

[3] J.D. Costa, M.B. de Sousa, J.J.N. Alves, B.O. Evaristo, 
R.A. Queiroga, A.X. Santos, T.M. Maciel, A.R.N. Campos, R.A.C. de Santana, and S. Prasad, J. Electrochem. Soc., 2018, 13(3), 2969-2975.

[4] T. Kuhn and L.V. Lewis, Gold Bull., 1988, 21(2), 140148.

[5] S. Catanzaro, and S.J. lacono, Method of electroforming a gold jewelry article, U.S. Patent 5393405, 1993.

[6] G. Bacquias, Gold Bull., 1982, 15(1) 4-12.

[7] O. Hosu, M.M. Bârsan, C. Cristea, R. Săndulescu, and C.M.A. Brett, Electrochim. Acta, 2017, 232(4), 285-296.

[8] O. Hosu, M.M. Bârsan, C. Cristea, R. Săndulescu, and C.M.A. Brett, Electrochim. Acta, 2017, 184(3), 39193928.

[9] B. Huo, S. Tong, and Y. Li, Int. J. Syst. Sci., 2013, 44(6), 2365-2374.

[10] C.E. Bocking Fimf. High speed selective jet electrodeposition of gold and gold alloys using single circular jets (Doctoral dissertation). Retrieved from C. Bocking., 1994.

[11] P.G. Globa, E.A. Zasavitsky, V.G. Kantser, S.P. Sidelinikova, and A.I. Dikusar, Mesoscale and Nanoscale Physics, 2007, 1(3), 707-715.

[12] W. Canning. Canning Handbook: Surface Finishing Technology, India, New Delhi, 2005.

[13] C. Shanthia, S. Barathanb, R. Jaiswala, and R.M. Arunachalamc, Indian J. Eng. Maters Sci., 2009, 16(2), 20-31.

[14] C.G. Kuo, C.Y. Hsu, J.H. Chen, and P.W. Lee, $A d v$. Mech. Eng., 2017, 11(2), 8-12.

[15] M. Kolli, and A. Kumar, Int. J. Eng. Sci. Technol., 2015, 8(3), 524-535.

[16] Ch.J. Raub, A. Knödler, and J. Lendvay, J. Am. Chem. Soc., 1976, 63(4), 35-47.
[17] J.C. Phipps, and F. Leaman, American Electroplaters and Surface Finishers Society, 1986.

[18] U. Erb, J. Nanostruct., 1995, 6(6), 533-541.

[19] C.V. Horn. Pulse Plating, Enthone-OMI Inc West Haven, CT, 2011.

[20] H. Karami, and H. Babaei, Int. J. Electrochem., 2012, 7(1), 601-613.

[21] Band I. Von A. Brenner, Electrodeposition of Alloys: Principles and Practice, Academic Press, New York London, 1963.

[22] D.W. Thomson, Gold alloy plating compositions and method, U.S. Patent 4179344, 1973.

[23] B. Bozzini, P.L. Cavallotti, and G. Giovannelli, Met. Finish., 2002, 100(6), 50-62.

[24] W.W. Kwong, T. Mun and K. Raymund, Electrolytes for the deposition of gold alloys, E.P. 1728898A2, 2006.

[25] B. Bozzini, and P.L. Cavallotti, Hydrodynamic effect in the electrodeposition of $\mathrm{Au}-\mathrm{Cu}-\mathrm{Cd}$ alloys, an experimental and numerical study, Transactions of the IMF, 2002, 78(5), 227-236.

[26] MacDermid Enthone Decorative Plating and Electroforming Processes for Fashion and Luxury Applications, MacDermid Enthone Industrial Solutions, 2017.

[27] B. Bozzini, and P.L. Cavallotti. Electrodeposition and characterization of Au-Cu-Cd alloys, J. Appl. Electrochem., 2001, 31(6), 897-908.

[28] L. Curtis. Electroforming (Jewelry Handbooks), A \& C Black Visual Arts English, 2013.

[29] J. Dornhofz, G.A. Urban and J. Kieninger, J. Electrochem. Soc., 2019, 166(5), 3001-3012.

[30] M. Sajjadnejad, H. Omidvar, and M. Javanbakht, Int. J. Electrochem. Sci., 2017, 12(2), 3635-3643. 